\section{Discovery and Characterization of a Turf-type Triploid Seashore Paspalum}

\author{
Brian M. Schwartz ${ }^{1,6}$ \\ Department of Crop and Soil Sciences, University of Georgia, 2360 \\ Rainwater Road, Tifton, GA 31793
}

\author{
Ryan N. Contreras ${ }^{1}$ \\ Department of Horticulture, OR State University, 4017 Agricultural and Life \\ Sciences Building, Corvallis, OR 97331
}

Karen R. Harris-Shultz ${ }^{2}$

Crop Genetics and Breeding Research Unit, USDA-ARS, 115 Coastal Way, Tifton, GA 31793

\author{
Douglas L. Heckart ${ }^{3}$ \\ Department of Crop and Soil Sciences, University of Georgia, 111 Riverbend \\ Road, Athens, GA 30602
}

\section{Jason B. Peake ${ }^{4}$}

Department of Agricultural Leadership, Education, and Communication, University of Georgia, 2356 Rainwater Road, Tifton, GA 31793

Paul L. Raymer ${ }^{5}$

Department of Crop and Soil Sciences, University of Georgia, 1109 Experiment Street, Griffin, GA 30223

Additional index words. carbol fuchsin, cytology, DAPI, flow cytometry, Paspalum vaginatum, PI, polyploid, turfgrass

\begin{abstract}
Seashore paspalum is a salt tolerant, predominately diploid $(2 n=2 x=20)$ species that is well adapted to coastal regions in tropical and subtropical environments. Because a majority of the available cultivars are propagated vegetatively and most genotypes are cross-fertile, a sterile cultivar that does not produce segregating seedlings would benefit sod growers and turfgrass managers who demand uniformity for certification and performance. Therefore, an experiment was conducted to create a colchicine-induced polyploid seashore paspalum. One triploid $(2 n=3 x=30)$ genotype (11-TSP-1) was identified and remains stable. Although there is a possibility that this event was triggered by the colchicine treatment, a more likely explanation is that it resulted from the union of a reduced and an unreduced gamete. Pollen shed was observed from 11-TSP-1 in 2011, but individual pollen grains stained with iodine-potassium iodide were irregularly shaped and typically had lower starch content than pollen from several diploid cultivars. The leaf width of 11-TSP-1 was statistically equal to that of the seashore paspalum cultivar SeaStar, indicating its potential for use as a fine turf. 11-TSP-1 had both superior visual color and a dark green color index when compared with 'SeaStar'. Future study of the reproductive fertility and more extensive field testing of this genotype should be carried out to determine its turfgrass potential. Chemical names used: $4^{\prime}$, 6-diamidino-2-phenylindole (DAPI), dimethyl sulfoxide (DMSO), iodine-potassium iodide ( $\left.\mathrm{I}_{2}-\mathrm{KI}\right)$, propidium iodide (PI).
\end{abstract}

Received for publication 21 Mar. 2013. Accepted for publication 15 Oct. 2013.

The authors would like to thank Byron Burson, Wayne Hanna, and Kevin Kenworthy for their discussion and advice regarding the cytogenetics and breeding of Paspalum species.

${ }^{1}$ Assistant Professor.

${ }^{2}$ Research Geneticist.

${ }^{3}$ Graduate Student.

${ }^{4}$ Associate Professor.

${ }^{5}$ Professor

${ }^{6}$ To whom reprint requests should be addressed; e-mail tifturf@uga.edu. because of its small leaf size and stoloniferous growth habit (Morton, 1973). This species has been widely characterized as a diploid $(2 n=$ $2 x=20$ ) in many cytological studies (Bashaw et al., 1970; Brown, 1948; Burson et al., 1973; Löve, 1981; Löve, 1982; Tateoka, 1962), although Gould (1975) also reported a $2 n=$ 40 chromosome number for $P$. vaginatum. There are also two accounts from India describing chromosome numbers of $2 n=40$ (Löve, 1977) and $2 n=60$ (Löve, 1975). Paspalum distichum L. and $P$. vaginatum have been misidentified in the past because of their morphological similarities. The absence of pubescence on the glumes and adaptation to brackish habitats have been the primary characteristics used to identify seashore paspalum and distinguish these two species (Brown, 1948; Evers and Burson, 2004). The most commonly reported chromosome numbers for $P$. distichum are $2 n=40$ and $2 n=60$ (Quarin and Burson, 1991).

Although a great deal is known about the cross-compatibility of $P$. vaginatum with other Paspalum species, only recently has research been completed on the mechanisms of self-incompatibility within, and level of fertility among, varieties of seashore paspalum (Wang, 2012). This work highlights the advantages of self-incompatibility and crossfertility with regard to crop improvement through plant breeding, but also reveals potential issues for variety purity and field inspection when different genotypes are grown in close proximity. A model for producing sterile triploid $(2 n=3 x=27)$ bermudagrass hybrids by crossing tetraploid genotypes [C. dactylon (L.) Pers.] with diploids (C. transvaalensis Burtt-Davy) has been in place for over 50 years and has had tremendous impact on the evolution of vegetative plant propagation and the buildup of an industry capable of growing, certifying, marketing, and profiting from the sale of this warm-season turfgrass (Hanna and Anderson, 2008). Because ploidy variation has not been documented in available turf-type seashore paspalum germplasm, the objective of several experiments carried out at the University of Georgia was to induce polyploidy in this species using colchicine seed treatments.

\section{Materials and Methods}

Colchicine Treatment and Seed Germination. Diploid $(2 n=2 x=20)$ Experimental Hybrid 2 seashore paspalum seeds were subjected to a $0.1 \%$ colchicine $+2.0 \%$ dimethyl sulfoxide (DMSO) treatment during 2010. Experimental Hybrid 2 is a heterozygous F1 hybrid resulting from open pollination between the self-incompatible breeding lines PI 509018-1 and AP-10, a clonal line derived from the cultivar Adalayd. A total of 8000 seeds were treated for $24 \mathrm{~h}$ on a laboratory bench at $21^{\circ} \mathrm{C}$ in $9-\mathrm{cm}$ glass petri dishes, divided equally among four replications. An untreated control to determine the effects of colchicine on germination was not performed. Seeds were then individually transplanted from petri dishes using forceps and planted in $6.4 \mathrm{~cm}$ diameter 
clay pots in a glasshouse on the University of Georgia, Tifton Campus. Each seed was pressed $\approx 0.3 \mathrm{~cm}$ into steam-sterilized Tifton sandy loam (fine-loamy, siliceous, thermic Plinthic Kandrudults) soil and watered as needed to maintain adequate soil moisture. Final germination counts were taken 3 months after planting.

Flow Cytometry. Flow cytometry analysis was used to screen all treated seashore paspalum seedlings for changes in genome size as compared with the DNA content of 'Sea Spray', a diploid $(2 n=2 x=20)$ seeded cultivar. To expedite the screening process, bulk samples of up to five seedlings and 'Sea Spray' were analyzed simultaneously. All plants were characterized as diploids in bulked samples where a single Gap1 peak was observed. When multiple peaks were observed in a bulked analysis, plants were reanalyzed individually with and without tissue of BA433 zoysiagrass [Zoysia pacifica (Goudswaard) M. Hotta \& Kuroki, 2C $=0.85$ pg (Schwartz et al., 2010)] to determine their relative DNA content and to infer ploidy level. Plants identified as other than diploid were then selected for more precise measurement of $2 \mathrm{C}$ nuclear DNA content. A putative polyploid (11-TSP-1) as well as the cultivars Sea Spray and SeaStar were analyzed in this manner using Pisum sativum $\mathrm{L}$. 'Ctirad' $[2 \mathrm{C}=8.76 \mathrm{pg}$ (Greilhuber et al., 2007)] as an internal standard. The mean 2C nuclear DNA content of each genotype was calculated using three replicates and was adjusted based on the peak of the internal standard by taking the ratio of the plant sample peak mean to the 'Ctirad' peak mean, and then multiplying by $8.76 \mathrm{pg}$. Below is a more descriptive explanation of the flow cytometry analyses.

About $1 \mathrm{~cm}^{2}$ of fresh tissue from a mature leaf from each genotype (and a plant standard in some analyses) was evaluated using flow cytometry. Leaf tissue was chopped with a double-edged razor blade in a petri dish with $500 \mu \mathrm{L}$ of nuclei extraction buffer for $\approx 60$ s. For the initial ploidy level screening, a CyStain ultraviolet Precise P kit was used (Partec GmbH, Münster, Germany). To calculate actual 2C nuclear DNA contents, a CyStain PI Absolute P kit was used (Partec $\mathrm{GmbH}$ ). In either case the resulting solution, containing isolated nuclei, was pipetted into a 5-mL test tube through a $50-\mu \mathrm{m}$ nylon mesh filter cap. Nuclei to be tested for only ploidy level were stained with $1.6 \mathrm{~mL}$ of $4^{\prime}$, 6-diamidino-2phenylindole (DAPI) buffer, incubated at $21{ }^{\circ} \mathrm{C}$ for a minimum of $10 \mathrm{~min}$, and analyzed by flow cytometry at the University of Georgia, Tifton Campus, on a PASIII cytometer (Partec $\mathrm{GmbH}$ ). For screening purposes, the DNA peak data were generally based on the fluorescence of between 2000 and 5000 scanned particles. For those samples that were subsequently reanalyzed for $2 \mathrm{C}$ nuclear DNA content, nuclei were stained with a $2.0 \mathrm{~mL}$ solution containing $0.3 \%$ ribonuclease (RNase) and $0.6 \%$ propidium iodide (PI). Samples were incubated at $4{ }^{\circ} \mathrm{C}$ for a minimum of $1 \mathrm{~h}$ and analyzed by flow cytometry at Oregon State University on a CyFlow ${ }^{\circledR}$ Ploidy Analyzer
(Partec GmbH). These DNA peak data were generated by scanning a minimum of 10,000 fluorescing particles.

Cytology. The chromosome number of 'Sea Spray' was determined using pollen mother cell (PMC) squashes. In preparation for screening PMCs, inflorescences were collected before they emerged from the flag leaf. Once harvested, individual racemes were fixed by immersion in $100 \%$ ethanol and glacial acetic acid $(6: 1 \mathrm{v} / \mathrm{v})$ for a period of $24 \mathrm{~h}$. Racemes were then rinsed with and stored in $70 \%$ ethanol at $4{ }^{\circ} \mathrm{C}$. Anthers were dissected from florets, macerated on a slide in modified carbol fuchsin stain (Kao, 1975), and squashed beneath a cover glass to observe PMCs undergoing meiosis. At least five cells in metaphase I or anaphase I were observed to determine the chromosome number.

The somatic chromosome numbers of 'Sea Spray', 'SeaStar', and 11-TSP-1 were also determined using root tip squashes collected from plants grown in pots filled with perlite. After a $24 \mathrm{~h}$ pretreatment in $3 \mathrm{~mm} 8$ hydroxyquinoline (Fisher Scientific, Suwanee, GA) and $0.24 \mathrm{~mm}$ cycloheximide (Acros Organics, Morris Plans, $\mathrm{NJ}$ ) at $4{ }^{\circ} \mathrm{C}$, roots were fixed in Carnoy's solution $[100 \%$ ethanol, chloroform, and glacial acetic acid $(6: 3: 1 \mathrm{v} / \mathrm{v} / \mathrm{v})]$ for $12 \mathrm{~h}$ at $25{ }^{\circ} \mathrm{C}$. Roots were thoroughly rinsed in deionized water before transferred to $70 \%$ ethanol at $4{ }^{\circ} \mathrm{C}$ for longterm storage. As time permitted, individual root tips were rinsed, excised on a glass slide with a razor, and incubated for $4.5 \mathrm{~h}$ at $37{ }^{\circ} \mathrm{C}$ in an enzyme mixture of $0.5 \%$ cellulose (Karlan Research, Torrance, CA), $0.5 \%$ cytohelicase (Sigma-Aldrich Co., St. Louis, MO), and $0.5 \%$ pectolyase Y-23 (Karlan Research), in $50 \mathrm{~mm}$ citrate buffer at $\mathrm{pH} 4.5$ to facilitate cell wall degradation. After the enzyme digestion, roots were rinsed and transferred to a glass slide where a razor blade was used to remove the root cap from each root. The meristematic cells concentrated behind the root cap were immediately covered with a single drop of modified carbol fuchsin stain (Kao, 1975) and a cover glass before squashing. Chromosomes of 10 cells were counted to determine the chromosome numbers using a Carl Zeiss AxioImager (Carl Zeiss MicroImaging $\mathrm{GmbH}$, Jena, Germany). Photomicrographs were taken using an AxioCam MRm (Carl Zeiss MicroImaging GmbH) and processed using AxioVision FRET software Version 4.7.2 (Carl Zeiss MicroImaging $\mathrm{GmbH}$ ).

Morphological Measurements. The starch content of pollen grains from seedheads of 'Sea Spray' and 11-TSP-1 grown in a glasshouse was determined by staining pollen deposited onto microscope slides with $2 \%$ iodine-potassium iodide $\left(\mathrm{I}_{2}-\mathrm{KI}\right)$ on 30 June 2011. Quantitative measurements of percent pollen stainability or pollen diameter were not estimated in this research.

Turfgrasses are commonly characterized by their leaf widths and color. A preliminary investigation of these traits was conducted in $5 \mathrm{~m} \times 6 \mathrm{~m}$ field plots of 'SeaStar' and 11TSP-1 that were initially planted on $13 \mathrm{Apr}$. 2011 as $2.5 \mathrm{~cm}$ plugs on $30 \mathrm{~cm}$ centers. 'Sea
Spray' was not included in this evaluation of vegetatively propagated genotypes because it is only established by seed. During the 2012 growing season, this test was fertilized with $16 \mathrm{~N}-1.7 \mathrm{P}-6.6 \mathrm{~K}$ at a rate of $2.4 \mathrm{~g} \mathrm{~N} / \mathrm{m}^{2}$ $\left(0.5 \mathrm{lbs} \mathrm{N} / 1000 \mathrm{ft}^{2}\right)$ per month from March to October. These plots were reel mowed at $1.3 \mathrm{~cm}(0.5 \mathrm{in})$ three times per week until mowing was halted in mid-August for 2 weeks before the measurement of leaf widths and color on 4 Sept. 2012. A digital caliper was used to measure the widest section of the second fully expanded leaf on 40 random phytomers of each cultivar. Leaf color was visually rated on a scale of 1 to 9 with $1=$ brown, $5=$ acceptable, and $9=$ dark green in 18 randomly selected $0.5 \mathrm{~m}^{2}$ areas within the $5 \mathrm{~m} \times 6 \mathrm{~m}$ field plots of each cultivar. Digital image analysis as described by Karcher and Richardson (2003) was used to calculate the dark green color index (DGCI) of the same $0.5 \mathrm{~m}^{2}$ areas that were visually rated for color. The distribution for all data was assessed with a histogram and normal probability plot for normality. The experimental design was a completely randomized design and an analysis of variance was performed on each of the measured traits to test whether genotypes varied. Means were separated using a Fisher's least significant difference (LSD) when the main effect "genotype" was found to be significant.

\section{Results}

Colchicine Treatment Experiments. 'Sea Spray' was confirmed to be a diploid $(2 n=$ $2 x=20$ ) by flow cytometry analysis (Fig. 1A) and PMC chromosome squashes (Fig. 1B).

Only 1450 of the 8000 Experimental Hybrid 2 seeds germinated (18.1\%) within 3 months after treatment with the $0.1 \%$ colchicine $+2.0 \%$ DMSO solution. Initial flow cytometry analysis of this group identified one genotype (11-TSP-1) with a relative genome size $\approx 1.5 \times$ that of the diploid cultivar Sea Spray (Fig. 1C) in the seedlings evaluated after the colchicine treatment. Root tip chromosome squashes confirmed that 11TSP-1 was a triploid $(2 n=3 x=30)$ (Fig. 1D). Precise genome sizing performed by analysis of PI-stained nuclei determined that the 2C nuclear DNA contents of 11-TSP-1, 'Sea Spray', and 'SeaStar' to be $2.25 \mathrm{pg}, 1.50 \mathrm{pg}$, and $1.49 \mathrm{pg}$, respectively (Table 1 ).

Morphological Experiments. Generally, a higher number of uniformly sized and stained pollen grains were harvested from 'Sea Spray' (Fig. 2A and B) than 11-TSP-1 (Fig. 2C and $\mathrm{D}$ ) based on preliminary observations of starch stainability performed during the summer of 2011. Fewer pollen grains shed from 11-TSP-1 and a continuum of starch staining, from unstained to completely stained, was observed. Additionally, these pollen grains were predominately joined together in clusters and varied greatly with regards to their diameter and shape when compared with pollen grains of 'Sea Spray'.

No significant variation $(P \geq 0.05)$ in leaf blade widths was observed among the genotypes 11-TSP-1 and 'SeaStar' (Table 1). 


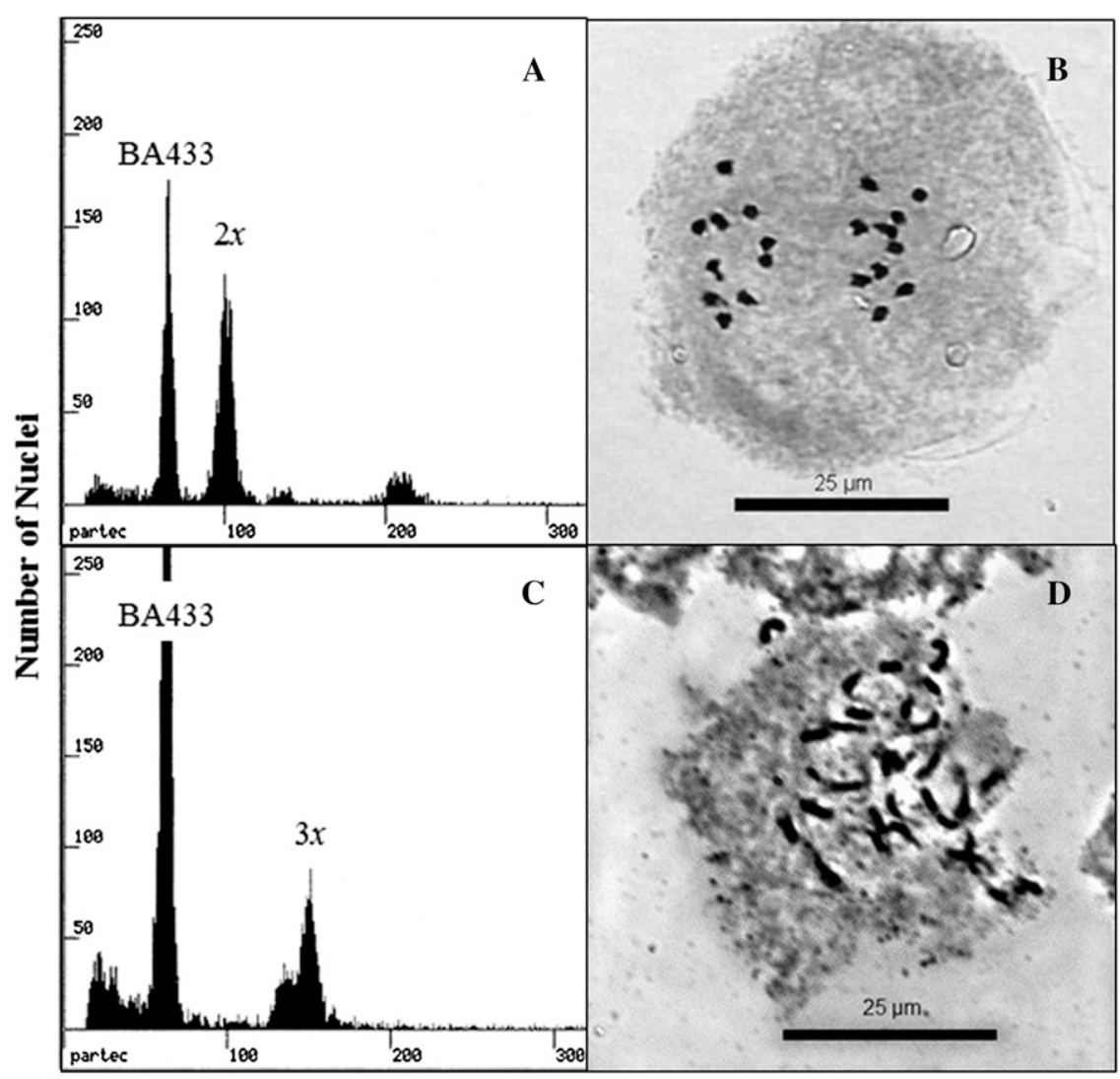

Relative DNA Content

Fig. 1. Histograms of relative DNA content generated using flow cytometry (A and $\mathbf{C}$ ) and photomicrographs of chromosome spreads (B and D) taken at $\times 1000$ magnification. (A) Diploid $(2 n=2 x=20)$ 'Sea Spray' seashore paspalum and BA433 zoysiagrass analyzed together. (B) 'Sea Spray' seashore paspalum in anaphase I of meiosis. (C) Triploid $(2 n=3 x=30) 11$-TSP-1 seashore paspalum and BA433 zoysiagrass analyzed together. (D) 11-TSP-1 paspalum in prometaphase of mitosis.

Table 1. Mean 2C nuclear DNA content, leaf blade width, and leaf color of a triploid $(2 n=3 x=30)$ seashore paspalum genotype as compared with two diploid $(2 n=2 x=20)$ cultivars as determined from field plots during 2012.

\begin{tabular}{lccccc}
\hline Genotype & $\begin{array}{c}\text { Chromosome } \\
\text { number count }\end{array}$ & $\begin{array}{c}\text { 2C DNA } \\
\text { content }(\mathrm{pg})\end{array}$ & $\begin{array}{c}\text { Leaf blade } \\
\text { width }(\mathrm{mm})\end{array}$ & $\begin{array}{c}\text { Visual colorw } \\
\text { rating }\end{array}$ & DGCI $^{\mathrm{w}}$ index \\
\hline $11-$ TSP-1 & 30 & $2.25 \pm 0.03^{\mathrm{z}}$ & $2.2 \mathrm{a}^{\mathrm{y}}$ & $8.5 \mathrm{a}$ & $0.71 \mathrm{a}$ \\
'SeaStar' & 20 & $1.50 \pm 0.03$ & $2.3 \mathrm{a}$ & $7.6 \mathrm{~b}$ & $0.70 \mathrm{~b}$ \\
'Sea Spray' & 20 & $1.49 \pm 0.02$ & ND $^{\mathrm{x}}$ & ND & ND \\
$\%$ CV & - & - & 15.9 & 6.3 & 1.59 \\
\hline
\end{tabular}

${ }^{2} 2 \mathrm{C}$ nuclear DNA content $\pm \mathrm{sE}$.

'Means within a column followed by the same letter are not different at $P<0.05$ according to Fisher's LSD. ${ }^{\mathrm{x}}$ Not determined.

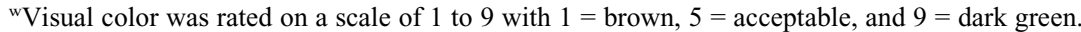

${ }^{\vee}$ Dark green color index (Karcher and Richardson, 2003).

However, these cultivars differed for both visual color $(P \leq 0.0001)$ and DGCI $(P \leq$ 0.05). 11-TSP-1 was darker green (8.5) than 'SeaStar' (7.6) according to visual ratings. The ranking and statistical separation of genotypes for DGCI corresponded to the visual color ratings (Table 1).

\section{Discussion}

This study involved the treatment of 8000 diploid $P$. vaginatum seeds with colchicine, yet no artificially induced tetraploid genotypes were identified. A question that remains is whether the triploid genotype that we describe (11-TSP-1) was a product of the colchicine seed treatment in 2010 , or some other means. Gaulden and Carlson (1946) estimated that colchicine is only effective for doubling chromosome numbers if mitosis is arrested in exactly the right stage of mitosis, very early in the differentiation process after seed germination. It is possible that an imperfect mitotic division at anaphase of the first cell cycle could have resulted in a plant with 30 chromosomes. A more plausible explanation may be that 11-TSP-1 arose from the union of a normal gamete with an unreduced egg or pollen grain $\left(\mathrm{B}_{\mathrm{III}}\right.$ or $2 n+n$ hybridization) stemming from nondisjunction of chromosomes during the reductional division of meiosis I, or the equational division of meiosis II. This hypothesis would be further substantiated if chromosomes primarily associate as trivalents during metaphase I of meiosis. Alternatively, the observation of one or more quadravalents would indicate that colchicine treatment had a role in the creation of 11-TSP-1. Analysis of meiosis in this genotype may not only reveal its origin but further explain the wide range in pollen sizes and stainability that were observed. None of the thousands of pollen grains that were analyzed from interspecific $P$. vaginatum hybrids were stained by $\mathrm{I}_{2}-\mathrm{KI}$ solutions, indicating they were sterile (Burson, 1981a; Burson, 1981b; Burson and Bennett, 1972; Burson et al., 1973; Quarin and Burson, 1983). Intensive efforts to cross- and self-pollinate 11-TSP-1 would help to understand its fertility, mode of reproduction, and value as a parent in our breeding program.

The 2C nuclear DNA content for both 'Sea Spray' and 'SeaStar' ( $\approx 1.50 \mathrm{pg})$ corresponds well with the reported genome sizes of other diploid Paspalum species (Arumuganathan et al., 1999; Vaio et al., 2007). Based on the average 2C nuclear DNA content of these two diploid seashore paspalum cultivars, the expected value of a triploid genotype would be $2.24 \mathrm{pg}$, which is within the standard error of the mean $2 \mathrm{C}$ nuclear DNA content of 11TSP-1 (Table 1). Regular testing for ploidy level stability in 11-TSP-1 will be important because this genotype could become chimeric (partially diploid and triploid) over time if it is actually a colchicine-induced triploid. There has been no indication of a complete or partial reversion to the diploid level during periodic flow cytometry analyses to reverify ploidy level during 2011, 2012, and 2013.

Leaf blade width measurements were taken on field plots maintained at a $1.3 \mathrm{~cm}(0.5 \mathrm{in})$, a mowing height commonly found on golf course fairways, to determine if 11-TSP-1 has potential as a turfgrass. The triploid genotype 11-TSP-1 had a leaf width of $2.2 \mathrm{~mm}$, which was not different from that of 'SeaStar' (Table 1). These leaf widths are slightly smaller than the 3 to $8 \mathrm{~mm}$ range in leaf width described by Hitchcock (1950) for P. vaginatum, although this may be expected as turftype seashore paspalum cultivars and the parents of Experimental Hybrid 2 were selected for diminutive plant structure. Generally, the morphological characteristics of diploid and triploid hybrids created by crossing $P$. vaginatum with other Paspalum species have had intermediate phenotypes to the two parents and were not well suited for use as turf (Burson, 1981a; Burson, 1981b; Burson and Bennett, 1972; Burson et al., 1973). Leaf color is an important factor in the overall quality of a turfgrass. The dark green color of 11-TSP-1 is very evident in the field as indicated by visual ratings and digital image analysis (Table 1). This has been the most obvious positive attribute of this grass during preliminary testing. Further study of the plant morphology, management requirements, production quality, and adaptation of this triploid genotype would clarify if 


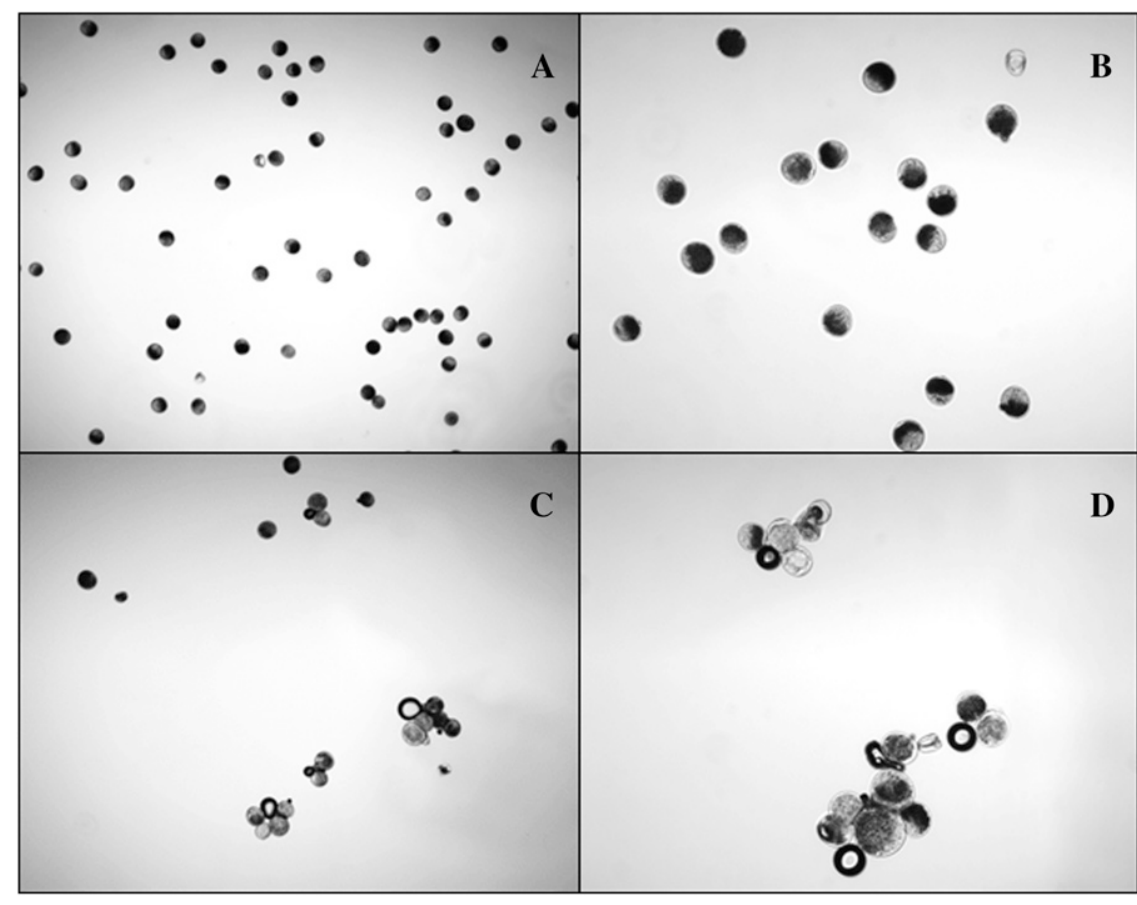

Fig. 2. Photomicrographs of iodine-potassium iodide stained pollen grains. Diploid $(2 n=2 x=20)$ 'Sea Spray' seashore paspalum at (A) $\times 100$ magnification and $(\mathbf{B}) \times 400$ magnification. Triploid $(2 n=3 x=$ 30) 11-TSP-1 seashore paspalum at $(\mathbf{C}) \times 100$ magnification and $(\mathbf{D}) \times 400$ magnification.

11-TSP-1 has value beyond that of being an interesting germplasm line.

The long-term goals of this research are to increase the genetic variability available for improvement of seashore paspalum and ultimately to develop new cultivars. More work should be done to create additional polyploid $P$. vaginatum plants from several populations with different genetic backgrounds. If efforts to double the chromosome number of this species using colchicine continue to fail, we could possibly use the methods Burton and Hanna (1986) described to create tetraploid $P$. notatum plants by pollinating a triploid genotype with diploid pollen. Furthermore, apomixis in the Paspalum genus has been the subject of extensive research and evidence exists that increased ploidy level, specifically autopolyploidy, has been associated with the expression of this trait (Quarin et al., 2001; Quarin et al., 1998). Additional investigation into the discovery or induction of an apomictic mode of reproduction, even in the facultative state, in seashore paspalum would be warranted if it enabled the preservation of hybrid vigor through clonal propagation by seed rather than vegetative plant materials in the future.

\section{Literature Cited}

Arumuganathan, K., S.P. Tallury, M.L. Fraser, A.H. Bruneau, and R. Qu. 1999. Nuclear
DNA content of thirteen turfgrass species by flow cytometry. Crop Sci. 39:15181521.

Bashaw, E.C., A.W. Hovin, and E.C. Holt. 1970. Apomixis, its evolutionary significance and utilization in plant breeding, p. 245-248. In: Norman, M.J.T. (ed.). Proceedings of the 11th International Grassland Congress, Queensland, Australia. 13-23 Apr. 1970. Univ. Queensland Press, Australia.

Brown, W.V. 1948. A cytological study in the Gramineae. Amer. J. Bot. 35:382-395.

Burson, B.L. 1981a. Genome relations among four diploid Paspalum species. Bot. Gaz. 142:592596.

Burson, B.L. 1981b. Cytogenetic relationships between Paspalum jurgensii and P. intermedium, $P$. vaginatum, and $P$. setaceum var. ciliatifolium. Crop Sci. 21:515-519.

Burson, B.L. and H.W. Bennett. 1972. Cytogenetics of Paspalum urville $\times P$. juergensii and $P$. urvillei $\times P$. vaginatum hybrids. Crop Sci. 12:105-108.

Burson, B.L., H. Lee, and H.W. Bennett. 1973. Genome relations between tetraploid Paspalum dilatatum and four diploid Paspalum species. Crop Sci. 13:739-743.

Burton, G.W. and W.W. Hanna. 1986. Bahiagrass tetraploids produced by making (apomictic tetraploid $\times$ diploid $) \times$ diploid hybrids. Crop Sci. 26:1254-1256.

Evers, G.W. and B.L. Burson. 2004. Dallisgrass and other paspalum species, p. 681-713. In: Moser, L.E., B.L. Burson, and L.E. Sollenberger (eds.). Warm-season $\left(\mathrm{C}_{4}\right)$ grasses. Agronomy no. 45 .
Gaulden, M.E. and J.G. Carlson. 1946. Action of different concentrations of colchicine on spindle formation and chromosome arrangement as revealed in the living cell. Genetics 32:87.

Gould, F.W. 1975. The grasses of Texas. Texas A\&M University Press, College Station.

Greilhuber, J., E.M. Temsch, and J.M. Loureiro. 2007. Nuclear DNA content measurement, p. 67-101. In: Dolezěl, J., J. Greilhuber, and J. Suda (eds.). Flow cytometry with plant cells: Analysis of genes, chromosomes and genomes. Wiley-VCH, Weinheim, Germany.

Hanna, W.W. and W.F. Anderson. 2008. Development and impact of vegetative propagation in forage and turf bermudagrasses. Agron. J. 100: S-103-S-107.

Hitchcock, A.S. 1950. Manual of the grasses of the United States. 2nd ed. Revised by Chase, A. Miscellaneous Publication no. 200. United States Government Printing Office, Washington, DC.

Karcher, D.E. and M.D. Richardson. 2003. Quantifying turfgrass color using digital image analysis. Crop Sci. 43:943-951.

Kao, K.N. 1975. A nuclear staining method for plant protoplasts, p. 60-62. In: Gamborg, O.L. and L.R. Wetter (eds.). Plant tissue culture methods. Natl. Res. Council of Canada, Ottawa, Ontario, Canada.

Löve, A. 1975. IOPB chromosome number reports XLVIII. Taxon 24:367-372.

Löve, A. 1977. IOPB chromosome number reports LVI. Taxon 26:257-274.

Löve, A. 1981. Chromosome number reports LXX Taxon 30:68-80.

Löve, A. 1982. IOPB chromosome number reports LXXIV. Taxon 31:119-128.

Morton, J.F. 1973. Salt-tolerant silt grass (Paspalum vaginatum Sw.). Proc. Fla. State Hortic. Soc. 86:482-490.

Quarin, C.L. and B.L. Burson. 1983. Cytogenetic relations among Paspalum notatum var. saurae, $P$. pumilum, $P$. indecorum, and $P$. vaginatum. Bot. Gaz. 144:433-438.

Quarin, C.L. and B.L. Burson. 1991. Cytology of sexual and apomictic Paspalum species. Cytologia (Tokyo) 56:223-228.

Quarin, C.L., F. Espinoza, E.J. Martinez, S.C. Pessino, and O.A. Bovo. 2001. A rise of ploidy level induces the expression of apomixis in Paspalum notatum. Sex. Plant Reprod. 13:243249.

Quarin, C.L., G.A. Norrmann, and F. Espinoza. 1998. Evidence for autoploidy in apomictic Paspalum rufum. Hereditas 129:119-124.

Schwartz, B.M., K.E. Kenworthy, M.C. Engelke, A.D. Genovesi, R.M. Odom, and K.H. Quesenberry. 2010. Variation in 2C nuclear DNA content of Zoysia spp. as determined by flow cytometry. Crop Sci. 50:1519-1525.

Tateoka, T. 1962. A cytological study of some Mexican grasses. Bul. Torrey Bot. Club 89:7782.

Vaio, M., C. Mazzella, V. Porro, P. Speranza, B. Lopez-Carro, E. Estramil, and G.A. Folle. 2007. Nuclear DNA content in allopolyploid species and synthetic hybrids in the grass genus Paspalum. Plant Syst. Evol. 265:109-121.

Wang, N. 2012. Reproductive behavior of seashore paspalum (Paspalum vaginatum Sw.). University of Georgia, Athens, GA, MS Thesis. 